\title{
Building resilience in young people through meaningful participation
}

\author{
Kylie G. Oliver ${ }^{1}$, Philippa Collin², Jane Burns ${ }^{2,3}$ and Jonathan Nicholas ${ }^{2}$ \\ 1. School of Psychology, James Cook University, Singapore International Campus, Singapore \\ 2. The Inspire Foundation, Sydney, New South Wales, Australia
}

3. VicHealth Public Health Research Fellow, Gustav Nossal Institute, The University of Melbourne, Australia

\begin{abstract}
Building resilience in young people is an important goal if we are to strengthen capacity and promote skills that help to reduce mental health problems. One way to foster resilience in young people is through meaningful youth participation; that is, decision-making by young people that involves meaning, control, and connectedness. Whilst youth participation may occur in recognition of young people's rights to be involved in all decisions that affect them, meaningful participation can itself enhance a young person's sense of connectedness, belonging and valued participation, and thereby impact on mental health and well being. Based on its extensive experience working collaboratively with young people, the Inspire Foundation, in partnership with young people, has developed a flexible and diverse approach to youth participation. This paper outlines the theoretical and conceptual underpinnings of the model, and discusses the operationalisation of program goals, atmosphere and activities that seek to build resilience through meaningful youth participation.
\end{abstract}

Keywords

resilience, young people, youth participation, youth development, mental health

\section{Introduction}

Resilience refers to an individual's capacity to successfully adapt to change and stressful events in healthy and constructive ways (Catalano, Berglund, Ryan et al., 2002a; Garmezy, 1991). Resilience has been conceptualised as a dynamic process involving an interaction between both risk and protective processes that act to modify the effects of an adverse life event (Rutter, 1985, 1999). In this context, resilience does not so much imply invulnerability to stress, but rather an ability to recover from negative events (Garmezy, 1991).

Traditionally the tumultuous period between childhood and adulthood has been considered 'normal' adolescent development. Whilst the majority of young people transition from adolescence to adulthood without any major problems (Offer \& Schonert-Reichl, 1992), approximately 14 percent of Australian adolescents experience mental health problems (Sawyer, Arney, Baghurst et al., 2002). Building skills that help to promote resilience in young people, therefore, is an important strategy in the amelioration of mental health problems.

Resilience is not necessarily an innate attribute; rather it may be best described as an adaptive process involving interactions between risk and protective factors across multiple levels of an individual's lived experience (Olsson, Bond,

Contact: $\quad$ Philippa Collin, The Inspire Foundation, PO Box 1790, Rozelle, NSW, Australia. pippa@inspire.org.au

Citation: $\quad$ Oliver, K.G., Collin, P., Burns, J. \& Nicholas, J. (2006). Building resilience in young people through meaningful participation. Australian e-Journal for the Advancement of Mental Health 5(1) www.auseinet.com/journal/vol5iss1/oliver.pdf

Published by: Australian Network for Promotion, Prevention and Early Intervention for Mental Health (Auseinet) www.auseinet.com/journal

Received 19 April 2005; Revised 24 May 2006; Accepted 26 May 2006 
Burns et.al., 2003). Resilient individuals utilise a set of coping skills and resources that allow them to deal effectively with stress and the development of resilience occurs when there is an interaction between an individual and stress (Blum, 1998a). Researchers typically categorise resilient attributes into dispositional or personal characteristics (e.g., a sense of spirituality, positive social skills, and personal efficacy), family or social characteristics (e.g., connectedness to a parent or caregiver), and environmental characteristics (such as involvement in one's community, access to health services and the presence of caring adults) (e.g., Blum, 1998b; Garmezy, 1985). Resilient outcomes refer to particular patterns of functional behaviour despite risk (Olsson, et al., 2003). Good mental health, social competence, and functional capacity are examples of resilient outcomes (Garmezy, 1991).

Models of youth that have focused on correcting problems or remediating developmental incapacity and deficit have dominated many professional fields charged with developing youth policy (Damon, 2004). However, in the last two decades preventative approaches, including positive youth development, have sought to promote affirmative, supportive interventions that emphasise potentialities of young people (Catalano et al., 2002a; Damon, 2004). Prevention programs that aim to reduce risk and promote protective factors are designed to enhance resilience in young people. Traditionally young people have been the passive recipients of these programs, often delivered in the school, family or community and commonly targeting the promotion of one or more positive life skills. In more recent years, research has shown that young people have a greater sense of control, meaning, and connectedness when they are involved in the decisions affecting them (Wierenga, 2003). Involving young people in decision-making is commonly referred to as 'youth participation'.

\section{The Inspire Foundation and Reach Out!}

The Inspire Foundation is a not-for-profit organisation that was established in 1996 and has an 8-year track record of successfully running technology-based services that create opportunities for young people to help themselves and others. The flagship initiative,
Reach Out! (www.reachout.com.au) is an online service connecting young people and providing them with information, referrals to appropriate sources of help, and stories about how others manage mental health problems. With over 3.6 million individual visits to the Reach Out! website since 1998, and more than 130,000 individual visits in the month of March 2006 alone, Reach Out! has established itself as a preferred online source of mental health advice and support for young Australians.

Targeting 16-25 year olds, Reach Out! is also one of the few services specifically addressing the transition from adolescence to young adulthood. Currently 35 percent of young people across Australia aged 17-21 are aware of the Reach Out! service and 85 percent of those say that they would recommend it to a friend. One of its strengths, reflecting Inspire's underlying philosophy, is that it is developed with young people and talks to them via their preferred medium of communication - the Internet.

Participation is a central tenet of the Inspire Foundation and more than 330 young people from a variety of backgrounds aged 16 to 25 have been directly involved in the development and delivery of the Reach Out! service since 1999. 'Inclusiveness' is an organisational value and Inspire is formally committed to involving young people in meaningful ways through collaboration.

\section{The Reach Out! Youth Participation Model}

The Reach Out! Youth Participation model was established to ensure that young people can contribute to the development and delivery of Reach Out! The model is founded on the underlying principles of youth participation that emphasise the rights of young people to be involved in the making of decisions that affect them, and on positive youth development models that stress recognising capacity and building skills. A key feature of the Reach Out! model is the participation of young people at all levels of the program, ensuring that they are involved in developing ideas and making decisions on the program goals and activities. An action based research methodology has informed the development of the model which incorporates current best practice and ensures that young 
people are engaged in, and instigate, significant changes at all stages of development in the model.

There are two tiers in the Reach Out! model: Youth Advisory Boards and the Youth Ambassador Program. Both tiers seek to achieve the following objectives:

- Provide young people with meaningful opportunities to be involved in the work of Inspire;

- Provide young people with resources and training to engage in opportunities to participate; and,

- Strengthen positive mental health and wellbeing of participants by promoting self worth, responsibility, autonomy, accountability, self awareness, emotional competencies, membership and belonging, and civic and social competence.

\section{Youth Advisory Board}

The Youth Advisory Board is convened three times a year. Young people from around Australia are invited to sit on each Board, which lasts for twelve weeks. Young people selfnominate and apply online. Board members must be between 16 and 21 years old. Each Board consists of approximately 18 young people from rural, regional and metropolitan Australia. The Board constitution seeks to enable representation of the views and opinions of young Australians from diverse cultural and geographical areas. Board members communicate on secure online forums in open discussions with each other and Inspire Foundation staff. Typically, staff take a 'backseat' in Board discussions, but act as moderators and encourage discussion by raising questions and ideas, and provide support and advice.

Key activities of board members are: sharing and developing ideas for service development and delivery, marketing and promotion on online forums, attending training workshops, writing content for the site (including stories, interviews and fact sheets) and promoting the service in their communities.

\section{Youth Ambassador Program}

At the end of their three-month term on the Youth Advisory Board, members are invited to continue volunteering for Reach Out! by becoming Youth Ambassadors. The Youth Ambassador program atmosphere seeks to emphasise supportive relationships with adults and peers by focusing on sharing ideas and working together on and offline to help other young people through the Reach Out! service. The program seeks to build a sense of empowerment by enabling young people to determine their own levels of contribution. Young people are supported to develop their own ideas, goals and activities through working with each other and program staff. This means fostering open lines of communication for ideas through staff engagement with forums, over the phone and by email. Finally, young people are encouraged to participate in all aspects of service development and delivery, including evaluation and research, for example, presenting to donors and sponsors, having their story featured on the home page of the site or writing the Youth Ambassadors' report for the organisation's Annual Report (alongside the Executive Director and the Director of the Board). The breadth of involvement and control over activities that young people have provides important opportunities for skill development and recognition.

\section{Theoretical and conceptual underpinnings}

The conceptual framework informing the Reach Out! model draws on theory from the key areas of youth participation and youth development, with a focus on promoting protective factors that build capacity in young people and enhance resilience.

\section{Youth participation}

There are many models conceptualising young people's participation in decision-making. The most recognised is by Hart (1992) who has conceptualised youth participation in practice as a spectrum with forms of non-participation (for instance, manipulation or tokenism) at one end, and full participation, where young people initiate ideas and share decisions with adults, at the other (e.g., Hart, 1992; Krauskopf, 2000). In addition, youth participation requires recognising capacities and building skills (Lansdown, 2001) of young people. Meaningful participation occurs when there is meaning, control and connectedness (Wierenga, 2003). Meaning refers to doing something that has a bigger purpose and that the young person believes in. Control relates 
to making decisions, being heard and having the resources, skills and knowledge to see the task through and do it well. Connectedness is gained by working with others, and having a sense of belonging and positive relationships with adults and peers (Wierenga, 2003). Engaging in meaningful activities, experiencing control and autonomy, and feeling connected to one's community, are important contributors to the development of resilience (Catalano et al., 2002a).

Finally, as youth participation enhances feelings of control, meaning, and connectedness, it can contribute to building resilience and competencies in young people, as well as supporting several developmental processes (Dworken, Larsen \& Hansen, 2003), such as identity formation (Waterman, 1984), developing initiative (Heath, 1999; Larson, 2000), learning of emotion regulation (Catalano et al., 2002a), fostering social skills (Jarrett, 1998), and acquiring meaningful relationships with adults (Jarrett, 1995).

\section{Positive youth development}

Building on the operational definitions of youth development objectives developed by Catalano et al. (2002a), Roth and Brooks-Gunn (2003) posit that positive youth development programs have three core elements: program goals; program atmosphere; and program activities. Program goals include promoting social, academic, cognitive, and vocational competencies, increasing adolescents' confidence, self-esteem, and self-efficacy, encouraging connections to other people and communities, developing character through increasing self-control and morality, and fostering caring and compassion. Program atmosphere refers to an environment that encourages the development of supportive relationships with others, empowers youth, communicates expectations for positive behaviour, enables opportunities for recognition, and provides services that are stable and relatively long-lasting. Program activities include opportunities for skill development, engaging in real and challenging activities, broadening horizons, and increasing available supports.

Youth participation has been identified as an important component of achieving some of the objectives of positive youth development programs, such as prosocial involvement (Catalano et al., 2000a). Moreover, many studies on resilience conclude that young people acquire critical, adaptive skills not through instruction, but through experience (Olsson et al., 2003). The Reach Out! model incorporates the dimensions of meaningful youth participation to develop the program goals, atmosphere and activities. These in turn operationalise positive youth development objectives, which seek to build components of resilience as follows. Social and cognitive competency fall under what have been described as individual protective factors, and social connectedness and participation are examples of social and environmental protective factors (Olsson et al., 2003; Spence et al., 2005).

\section{Individual protective factors}

\section{Social competency}

Social competency refers to a range of interpersonal skills that help young people integrate thoughts, feelings and actions which lead to the achievement of social or personal goals (Catalano, Hawkins, Berglund et al., 2002b). Development of interpersonal skills relating to communication and conflict resolution, and opportunities to practise these skills, have been identified as the operationalisation of the goal of social competency (Roth \& Brooks-Gunn, 2003). These skills may specifically include learning about and recognising relevant social cues, accurately interpreting such cues and developing appropriate responses to interpersonal problems, and putting those into action (Elias, Weissberg, Hawkins et al., 1994).

Knowledge development. Youth Ambassadors work collaboratively with staff to develop content for the Reach Out! site and are engaged in the improvement and promotion of the service. This regularly involves young people researching and collating information on a range of mental health, social and health issues, which seeks to increase their capacity to understand and manage their own mental health needs and those of others.

Skills development. Skills development plays an integral role in the Reach Out! model. Skills workshops have been developed and implemented following the Youth Ambassadors' identification of key areas where they would like 
more training and support. These include training in presentation skills, media campaigning and interpersonal skills, using an evaluated training program. The workshops aim to increase the Youth Ambassadors' social, interpersonal, and presentation skills, in order to assist them in their volunteering and in their professional lives. They also seek to increase self-confidence, self-esteem, and self-efficacy, as a strategy for building skills and abilities to promote and contribute to Reach Out! and their communities, and to encourage commitment and active involvement in Reach Out!

\section{Cognitive competency}

Skills including problem-solving, decisionmaking, planning and goal-setting have been identified as indicators of cognitive competency and therefore contribute to the objectives of youth development (Roth \& Brooks-Gunn, 2003). These same skills have been identified as individual protective factors that contribute to positive adaptation associated with resilience (Spence, Burns, Boucher et al., 2005).

Self-driven involvement. Young people plan and manage their participation and contribution to Reach Out! Although the programs are flexible and require only a minimum level of participation from the Youth Ambassadors, young people are encouraged and given many opportunities to be involved in the different aspects of the work of the Foundation. Young people can customise their involvement to their own skill set and time constraints. They participate in training, goal setting and project planning, and develop action plans. Young people are provided with support from staff and their peers to follow through on their action plan ideas as a mechanism for contributing to Reach Out!

\section{Social and environmental protective factors}

\section{Social connectedness and participation}

Research has demonstrated that connectedness to a parent or family is predictive of positive health outcomes (Resnick, Bearman, Blum et al., 1997). Additionally, having the support of caring adults outside of the family is an important contributor to resilience (Blum, 1998a). More broadly, research finds that a sense of community and connectedness has been shown to be important in enhancing resilience and fostering positive mental health (Catalano et al., 2002b).

Research has also shown that youth programs with a focus on helping others improve academic and social outcomes and enhance self-concept and community values (Johnson, Beebe, Mortimer \& Snyder, 1998; Moore \& Allen, 1996). There is evidence that through drawing on their own experiences to help others, young people are better able to deal with, resolve, and gain some perspective on their own issues (Follman \& Muldoon, 1997). Helping others can also increase self-esteem (from the knowledge that one has something to offer), decrease dependency, and provide a sense of control and a feeling of social usefulness (Kohler \& Strain, 1990; Thoits \& Hewitt, 2001; Turner, 1999). In addition, peer support enables young people to develop effective coping skills and to receive social support from peers and adults (Greene \& Walker, 1997).

Providing opportunities for young people to develop positive relationships with caring adults, and more broadly strengthening relationships with other people including their peers, is considered an important goal of youth development (Roth \& Brooks-Gunn, 2003). As such, providing opportunities for young people to make and strengthen positive relationships can contribute to social and environmental protective factors.

Helping others and sense of community. Young people are engaged in activities that directly build Reach Out!, including writing content, developing ideas, making decisions about the strategic development of the service, and promoting Reach Out! in their communities. All activities are intended to strengthen the service and build awareness of the site and as such, contribute to helping other young people.

Through their participation in the program, Youth Ambassadors are encouraged to develop skills and knowledge about mental health issues that they can use in their role as site moderators on the Reach Out! public forums, with other Youth Ambassadors, and in their personal lives. Peer support training seeks to normalise the process of seeking help for problems.

A sense of community and connectedness to others is fostered through sharing ideas and 
working towards the achievement of a common goal. Face-to-face communication and regular online discussions facilitate the formation of new friendships and new interests.

Adult support. Inspire Foundation staff provide the Youth Ambassadors with support for Foundation activities, interpersonal concerns, and vocational pursuits. Youth Ambassadors receive advice and support from staff to develop an idea or initiative for Reach Out!, materials to carry out activities, help to plan and organise travel arrangements, and financial assistance to cover any costs. Youth Ambassadors often turn to Inspire Foundation staff to receive support for interpersonal issues. Counselling skills training is provided to staff to enable them to discuss sensitive issues and to provide referrals to appropriate sources of help. Finally, Inspire Foundation staff develop opportunities for the Youth Ambassadors to gain experience in a range of areas related to vocational pursuits (such as marketing, public speaking, writing, web design and development) and provide letters of reference and recommendation to potential employers. The program also seeks to enable young people to develop positive relationships with organisation supporters and partners. Youth Ambassadors are encouraged to work with staff and partners in relation to sponsorship, donor management, development and corporate volunteering, which can contribute to the development of positive relationships with other adults and organisations and provide them access to professional skills and resources.

\section{Conclusion}

The Reach Out! Youth Participation Model incorporates the three elements of youth development programs (that is, program goals, atmosphere, and activities) proposed by Roth and Brooks-Gunn (2003) to build resilience among young people. The goals of the Inspire Foundation Youth Programs include developing interpersonal and communication skills, increasing young volunteers' confidence, selfesteem, and self-efficacy, encouraging connections to other young people and adults in the community, and fostering caring and compassion. Program atmosphere is comprised of a supportive, learning environment that enables autonomous and self-driven involvement and recognition for contributions. Program activities include opportunities to develop and apply new skills, challenging and rewarding activities, and involvement in a range of youth related events and activities. Together, these specific program goals, atmosphere, and activities of the Inspire Foundation Youth Programs seek to promote resilience and enable the development of positive mental health.

\section{References}

Blum, R.W. (1998a). Healthy youth development as a model for youth health promotion: A review. Journal of Adolescent Health, 22, 368-375.

Blum, R.W. (1998b). Improving the health of youth: A community health perspective. Journal of Adolescent Health, 23, 254-258.

Catalano, R.F., Berglund, M.L., Ryan, J.A.M., Lonczak, H.S., \& Hawkins, J.D. (2002a). Positive youth development in the United States: Research findings on evaluations of positive youth development programs. Prevention and Treatment, 5(1), 15 [Article A]. Retrieved from http://content.apa.org/journals/pre/5/1/15

Catalano, R.F., Hawkins, J.D., Berglund, M.L., Pollard, J.A., \& Arthur, M.W. (2002b). Prevention science and positive youth development: Competitive or cooperative frameworks? Journal of Adolescent Health, 31, 230-239.

Damon, W. (2004). What is positive youth development? ANNALS of the American Academy of Political and Social Science, 591, 13-24

Dworken, J.B., Larsen, R., \& Hansen, D. (2003). Adolescents' accounts of growth experiences in youth activities. Journal of Youth and Adolescence, 32(1), 17-26.

Elias, M.J., Weissberg, R.P., Hawkins, J.D., Perry, C.L., Zins, J.E., Dodge, K.A., Kendall, P.C., \& Gottfredson, D.C. (1994). The school-based promotion of social competence: Theory, research, practice and policy. In R.J. Haggerty, N. Garmezy, M. Rutter, \& L. Sherrod (Eds.), Stress, Risk and Resilience in Children and Adolescents: Processes, mechanisms, and interventions. New York: Cambridge University Press (pp. 269-315).

Follman, J. \& Muldoon, K. (1997). Florida Learn and Serve 1995-96: What were the outcomes. NAASP Bulletin, 81, 29-36.

Garmezy, N. (1985). Stress resistant children: The search for protective factors. Journal of Child Psychology and Psychiatry and Allied Disciplines, Supplement 4, 213-233.

Garmezy, N. (1991). Resiliency and vulnerability to adverse developmental outcomes associated with 
poverty. American Journal of Behavioral Science, 34, 416-430.

Greene, J.W. \& Walker, L.S. (1997). Psychosomatic problems and stress in adolescence. Pediatric Clinics of North America, 44, 1557-1572.

Hart, R. (1992). Children's Participation: From Tokenism to Citizenship. Innocenti Essay No.4. Florence: UNICEF Innocenti Research Centre.

Heath, S.B. (1999). Dimensions of language development: Lessons from older children. In A.S. Masten (Ed.), Cultural Process in Child Development: The Minnesota Symposium on Child Development (Vol 29). Mahwah, NJ: Erlbaum (pp. 59-75).

Jarrett, R.L. (1995). Growing up poor: The family experiences of socially mobile youth in low-income African American neighbourhoods. Journal of Adolescent Research, 10, 111-135.

Jarrett, R.L. (1998). African American children, families, and neighbourhoods: Qualitative contributions to understanding developmental pathways. Applied Developmental Science, 2, 2-16.

Johnson, M.K., Beebe, T., Mortimer, J.T., \& Snyder, M. (1998). Volunteerism in adolescence: A process perspective. Journal of Research on Adolescence, 8, 309-332.

Kohler, F.W. \& Strain, P.S. (1990). Peer assisted interventions: early promises, notable achievements and future aspirations. Clinical Psychology Review, 10, 441-452.

Krauskopf, D. (2000). Youth service, participation and adolescent development. Paper presented at the Ford Foundation's Worldwide Workshop on Youth Involvement as a Strategy for Social, Economic and Democratic Development. Johannesburg: Knoxville Press.

Lansdown, G. (2001). Promoting children's participation in democratic decision-making Innocenti Insight, 6. Retrieved from

http://ideas.repec.org/p/ucf/innins/innins01-9.html

Larson, R. (2000). Towards a psychology of positive youth development. American Psychologist, 55, 170183.

Moore, C.W. \& Allen, J.P. (1996). The effects of volunteering on the young volunteer. The Journal of Primary Prevention, 17, 231-258.
Offer, D. \& Schonert-Reichl, K. A. (1992). Debunking the myths of adolescence: Findings from recent research. Journal of the American Academy of Child and Adolescent Psychiatry, 31(6), 1003-1014.

Olsson, C.A., Bond, L., Burns, J.M., Vella-Brodrick, D.A., \& Sawyer, S.M. (2003). Adolescent resilience: A concept analysis. Journal of Adolescence, 26, 1-11.

Resnick, M.D., Bearman, P.S., Blum, R.W., Bauman, K.E., Harris, K.M., Jones, J., Tabor, J., Beuhring, T., Sieving, R.E., Shew, M., Ireland, M., Bearinger, L.H., \& Udry, J.R. (1997). Protecting adolescents from harm: Findings from the National Longitudinal Study on Adolescent Health. The Journal of the American Medical Association, 278(10), 823-832.

Roth, J.L. \& Brooks-Gunn, J. (2003). Youth development programs: Risk, prevention and policy. Journal of Adolescent Health, 32, 170-182.

Rutter, M. (1985). Resilience in the face of adversity: Protective factors and resistance to psychiatric disorder. British Journal of Psychiatry, 34, 598-611.

Rutter, M. (1999). Resilience concepts and findings: Implications for family therapy. Journal of Family Therapy, 21, 119-224.

Sawyer, M.G., Arney, F.M., Baghurst, P.A., Clark, J.J., Graetz, B.W., Kosky, R.J., Nurcombe, B., Patton, G.C., Prior, M.R., Raphael, B., Rey, J., Whaites, L.C., \& Zubrick, S.R. (2002). Mental Health of Young People in Australia. Canberra: Commonwealth Department of Health and Aged Care.

Spence, S., Burns, J., Boucher, S., Glover, S., Graetz, B., Kay, D., Patton, G., \& Sawyer, M. (2005). The beyondblue Schools Research Initiative: Conceptual framework and intervention. Child and Adolescent Psychiatry, 13(2), 159-164.

Thoits, P.A. \& Hewitt, L.N. (2001). Volunteer work and well-being. Journal of Health and Social Behavior, 42, 115-131.

Turner, G. (1999). Peer support and young people's health. Journal of Adolescence, 22, 567-572.

Waterman, A. (1984). Identity formation: Discovery or creation? Journal of Early Adolescence, 4, 329341.

Wierenga, A. (2003). Sharing a New Story: Young People in Decision Making. Australian Youth Research Centre, Working Paper 23. Melbourne: The Foundation for Young Australians. 